\title{
Decision Support System For Computer Recommendations Using Web- Based Fuzzy Tahani Logic Method
}

\section{Sistem Pendukung Keputusan Untuk Rekomendasi Komputer Menggunakan Metode Logika Fuzzy Tahani Berbasis Web}

\author{
Farrell Ega Santosa, Farrell'), Ika Ratna Indra Astutik ${ }^{2)}$ \\ \{farrellsantosa98@gmail.com¹, ikaratna@umsida.ac.id ${ }^{2}$ \} \\ Universitas Muhammadiyah Sidoarjo, Sidokare Asri E-2¹, Universitas Muhammadiyah Sidoarjo, Durungbedug, Candi, \\ Sidoarjo ${ }^{2}$
}

\begin{abstract}
Nowadays people are familiar with computers and many use computers to support their needs, but many people do not understand the specifications of computers that suit their needs, so a web-based application is made that provides recommendations for computer specifications using fuzzy logic. This research method uses observation to obtain information about computer components. The results of this study indicate the recommendations for computer components, namely computer, monitors, keyboard, and mouse according to the user's wishes. The conclusion of this study, this website makes it easier for users to choose computer components.
\end{abstract}

Keywords - computer; fuzzy; tahini; web

Abstrak. Di zaman sekarang masyarakat sudah mengenal komputer dan banyak yang menggunakan komputer untuk menunjang kebutuhannya, namun banyak masyarakat yang kurang paham tentang spesifikasi komputer yang sesuai dengan kebutuhannya maka dibuatlah aplikasi berbasis web yang memberikan rekomendasi spesifikasi komputer menggunakan logika fuzzy tahani. Metode penelitian ini menggunakan observasi untuk memperoleh informasi mengenai komponen-komponen komputer. Hasil penilitian ini menunjukkan rekomendasi komponen komputer yaitu komputer, monitor, keyboard, dan mouse yang sesuai keinginan pengguna. Kesimpulan dari penelitian ini, web ini mempermudahkan pengguna dalam memilih komponen-komponen komputer.

Kata Kunci - computer; fuzzy; tahini; web

\section{Pendahuluan}

\section{A. Latar Belakang}

Penggunaan komputer di Indonesia pada umumnya sudah mengalami kenaikan, umumnya masyarakat Indonesia sudah bisa menggunakan komputer untuk memenuhi kebutuhannya, pada buku survey Badan Pusat Statistik berjudul "STATISTIK TELEKOMUNIKASI INDONESIA 2018", kepemilikan komputer dalam rumah tangga tahun 2018 mengalami kenaikan menjadi 20,05 persen, naik jika dibandingkan dengan tahun 2012 yang hanya sekitar 14,86 persen. Selama periode 2012-2018 tersebut kepemilikan komputer dalam rumah tangga mengalami peningkatan sekitar 1,04 persen per tahun.

Komputer berasal dari kata to compute yang diartikan menghitung. Menurut V.C. Hamacher, Z.G. Vranesic dan S.G. Zaky yang tergabung Computer Organization, komputer dijelaskan sebagai seperangkat mesin komputasi elektronik yang cepat sehingga mendapatkan sebuah informasi input digital, merangkainya disesuaikan dengan sebuah pemrograman yang disimpan di memorinya dan menghasilkan output informasi.

Komputer terbentuk dari beberapa bagian yang ditetapkan, termasuk komponen tambahan dan expansion card untuk memproses suatu fungsi tertentu pada computer. Tujuan utama dari sistem computer yaitu memproses data untuk menghasilkan informasi. Agar tujuan utama tersebut terlaksana, maka wajib ada elemen-elemen pendukung. Elemen-elemen tersebut brainware (manusia), 2 hardware (perangkat keras) dan software (perangkat lunak) [2].

Logika Fuzzy atau dikenal sebagai Fuzzy logic, merupakan suatu metode kecerdasan buatan. Yang dimana kecerdasan buatan tersebut adalah suatu sistem informasi yang berhubungan dengan pemodelan dan penyimpanan kecerdasan manusia dalam sebuah sistem teknologi informasi sehingga sistem informasi tersebut memiliki kecerdasan seperti yang manusia. Sistem ini bertugas menyelesaikan suatu masalah, biasanya diselesaikan melalui aktivitas intelektual manusia, seperti contoh, pengolahan citra, perencanaaan, peramalan, dan sebagainya [3].

Berdasarkan Latar belakang diatas, penulis membangun "Sistem Pakar Rekomendasi Komputer Menggunakan Metode Logika Fuzzy Tahani Berbasis Web" yang bertujuan memudahkan pengguna dalam memilih komponen komponen CPU sesuai dengan kebutuhan. 


\section{B. Rumusan masalah}

Permasalahan yang akan menjadi perhatian utama pada penelitian ini adalah "Bagaimana cara menciptakan Sistem Pendukung Keputusan Untuk Rekomendasi Komputer Menggunakan Metode Logika Fuzzy Tahani Berbasis Web?".

\section{Batasan masalah}

Agar penelitian ini lebih terarah sehingga pembahasan ini tidak menyimpang dari tujuan yang ingin dicapai, maka perlu adanya pembatasan masalah sebagai berikut :

1. Komponen-komponen yang digunakan sebagai rekomendasi komputer sebagai berikut :
a. CPU
b. Layar monitor 24 inch
c. Keyboard
d. Mouse

2. Pengambilan harga komponen-komponen komputer dilakukan pada tanggal 25 November 2020

3. Pengambilan data dilakukan dilokasi toko komputer CIPTA MANDIRI COMPUTER

4. Web ini hanya menunjukkan rekomendasi perangkat-perangkat komputer

\section{Tujuan penelitian}

Tujuan dari penelitian ini adalah untuk membuat system pendukung keputusan untuk rekomendasi komputer menggunakan metode logika fuzzy tahini berbasis web.

\section{METODE}

\section{A. Sistem Pendukung Keputusan}

Sistem pendukung keputusan diciptakan pertama kali oleh Michael S. Scoott Morton pada tahun 1970-an dengan istilah Management Decision System [1]) Sistem pendukung keputusan dibuat untuk mendukung seluruh tahap pengambilan keputusan mulai dari mencari masalah, memilih data yang sesuai, dan menentukan pendekatan yang dipakai dalam proses pengambilan keputusan, sampai mengevaluasi pemilihan alternative [6]

\section{B. Metode Logika Fuzzy}

Logika Fuzzy diperkenalkan oleh Prof. Lotfi Zadeh pada tahun 1965. Sebuah metode yang memiliki kemampuan untuk mengolah variable yang bersifat samar. Dalam logika fuzzy variable yang bersifat samar dapat direpresentasikan sebagai himpunan yang anggotanya adalah suatu nilai crisp dan derajat anggotanya dalam himpunan tersebut [4].

Proses-proses dalam logika fuzzy adalah fuzzifikasi, penalaran, dan defuzzifikasi:

a. Fuzzifikasi adalah proses mendapatkan derajat keanggotaan dari nilai numerik input (crisp).

b. Penalaran adalah sebuah proses untuk mendapatkan keluaran dari sebuah kondisi input dengan mengikuti aturaaturan (IF-THEN rules) yang ditetapkan disebut sebagai inference / reasoning.

c. Defuzzfikasi proses mengubah hasil penalaran berupa derajat keanggotaan output menjadi variable numerik kembali.

\section{Fungsi Keanggotaan}

(Kusumadewi.2006) mengatakan bahwa ada beberapa fungsi yang digunakan, adalah:

1. Representasi linier

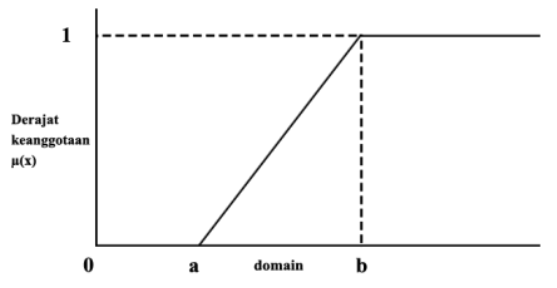

Fungsi keanggotaan :

Gambar 2.1 Representasi Linear Naik

$$
\begin{aligned}
\mu(x)=\{ & 0, x \leq a \\
& x-a / b-a, a \leq x \leq b \\
& 1, x \geq b
\end{aligned}
$$

Yang kedua, merupakan lawan dari yang pertama. Garis lurus diawali dengan nilai domain dengan derajat anggota tertinggi pada sisi kiri, kemudian berjalan menuju ke nilain domain yang mempunyai derajat anggota lebih rendah.

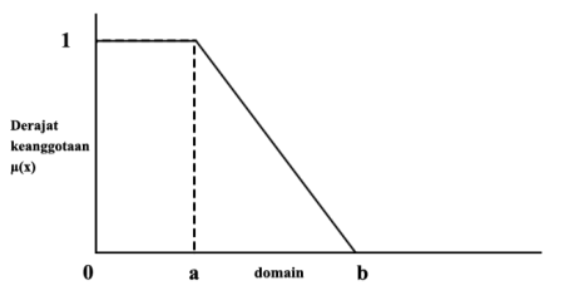


Fungsi keanggotaan :

Gambar 2.2 Representasi Liniear Turun

$$
\begin{aligned}
& \mu(x)=\{1, x \leq a \\
& b-x / b-a, a \leq x \leq b \\
& 0, x \geq b
\end{aligned}
$$

2. Representasi kurva segitiga

Fungsi keanggotaan :

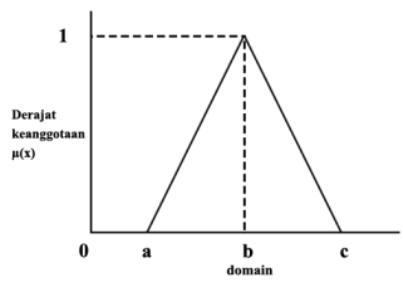

$\mu(x)=\{0, x \geq c$ atau $x \leq a$

$$
\begin{aligned}
& x-a / b-a, a<x<b \\
& c-x c-b, b<x<c
\end{aligned}
$$

3. Representasi kurva trapesium

Gambar 2.3 Representasi Kurva Segitiga

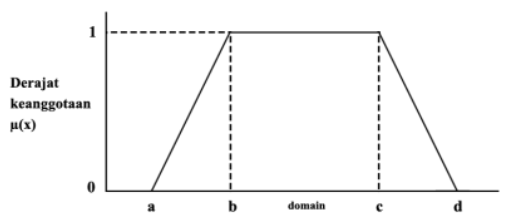

Fungsi keanggotaan :

Gambar 2.4 Representasi Kurva Trapesium

$$
\begin{aligned}
\mu(x)= & \{0, x \geq d \text { atau } x \leq a \\
& x-a / b-a, a<x<b \\
& d-x / d-c, c<x<d \\
& 1, b \leq x \leq c
\end{aligned}
$$

4. Representasi kurva bentuk bahu

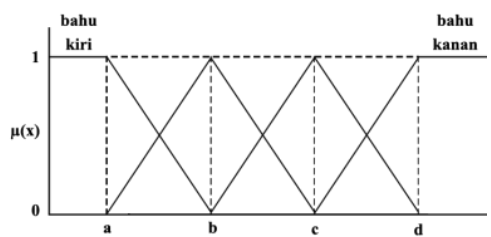

Gambar 2.5 Representasi Kurva Bentuk Bahu

\section{Fuzzy Model Tahani}

Langkah-langkah fuzzy tahani sebagai berikut [5].

1. Fuzzifikasi

Fuzzifikasi adalah sebuah proses dimana mengubah bilai masukan tegas menjadi nilai masukan fuzzy. Nilai masukan tegas dimasukan kedalam penyamaran yang dibentuk sehingga menghasilkan nilai masukan fuzzy.

Fungsi keanggotaan adalah sebuah kurva yang menunjukkan letak titik-titik masukan data ke nilai keanggotaannya atau disebut dengan derajat keanggotaan yang intervalnya antara 0 sampai 1 .

2. Penyusunan kriteria

Kriteria linguistic biasanya mengandung kata penghubung "and" dan "or". Kata "or" dihubungkan dengan operasi gabungan pada himpunan fuzzy, "and" dikaitkan dengan operasi irisan pada himpunan fuzzy. Data himpunan tegas pada setiap kriteria (x) diletakkan sesuai fungsi keanggotaan masing-masing pada variabel himpunan fuzzy sehingga data bisa diperoleh derajat anggotanya [7].

3. Penentuan nilai fire strength

Kriteria yang dinyatakan sebuah variabel dan himpunan fuzzy akan diolah menggunakan operasi himpunan fuzzy. 
4. Penentuan hasil rekomendasi

Nilai fire strength diperoleh pada langkah sebelumnya akan menjadi dasar keputusan rekomendasi. Apabila nilai fire strength lebih besar dari 0 adalah direkomendasikan dan jika nilainya terbesar maka itu adalah hasil rekomendasi terbaik.

\section{E. Flowchart}

Flowchart adalah representasi secara simbolik dari prosedur untuk menyelesaikan sebuah masalah, dengan adanya flowchart akan mempermudahkan user melakukan pemeriksaan bagian-bagian yang terlewatkan dalam analisis sesuatu masalah, selain itu fungsi flowchart adalah untuk alat berkomunikasi antar per orang yang bekerja dalam sebuah tim [8]

\section{F. DFD (Data Flow Diagram)}

Data Flow Diagram (DFD) adalah sebuah diagram dimana menggambarkan alur data dalam suatu entitas ke sistem atau system ke entitas [9].

\section{G. Basis Data}

Yang membedakan cara mereka berinteraksi terhadap sistem yaitu :

1. Programer Aplikasi

Pemakai berinteraksi dengan basisdata lewat Bahasa manipulasi data, yang bersamaan dengan program yang ditulis dalam Bahasa pemrograman inti.

2. User Mahir (Casual User)

Pengguna yang berinteraksi dengan sistem tanpa menulis modul program.

3. User umum (End User Naïve User)

Pengguna berinteraksi dengan sistem basis data lewat panggilan satu program aplikasi tetap yang telah ditulis sebelumnya.

4. User khusus (Specialized User)

Pengguna yang menulis aplikasi basisdata non konvensional, namun untuk keperluan khusus [10]

\section{HaSil dan Pembahasan}

\section{A. Flowchart}

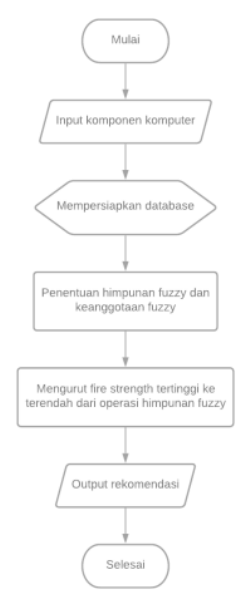

Gambar 3.1 Flowchart sistem keputusan

Penjelasan dari gambar 3.1 adalah penjelasan cara kerja sistem keputusan, langkah pertama pengguna memasukan input komponen komputer yang di inginkan, langkah kedua mempersiapkan database untuk memanggil data-data yang diperlukan, langkah ketiga menghitung himpunan fuzzy dan keanggotaan fuzzy, langkah ke empat menentukan fire strength dari hasil himpunan fuzzy dan keanggotaan fuzzy lalu mengurut nilai fire strength dari tertinggi ke terendah, langkah terakhir menampilkan output barang-barang yang direkomendasikan hasil perhitungan fire strength. 


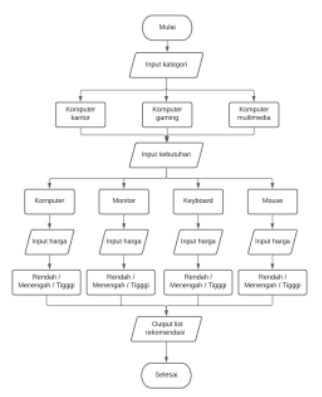

Gambar 3.2 Flowchart pada user

Penjalasan dari gambar 3.2 adalah pengguna memilih kategori yang di inginkan, apakah memilih komputer kantor, komputer gaming, atau komputer multimedia, selanjutnya memasukkan input kebutuhannya meliputi, komputer, monitor, keyboard, dan mouse, masing-masing barang tersebut menentukan golongan harga rendah, menengah, tinggi. Setelah memasukkan semua input maka muncul list rekomendasi barang-barang yang diinginkan.

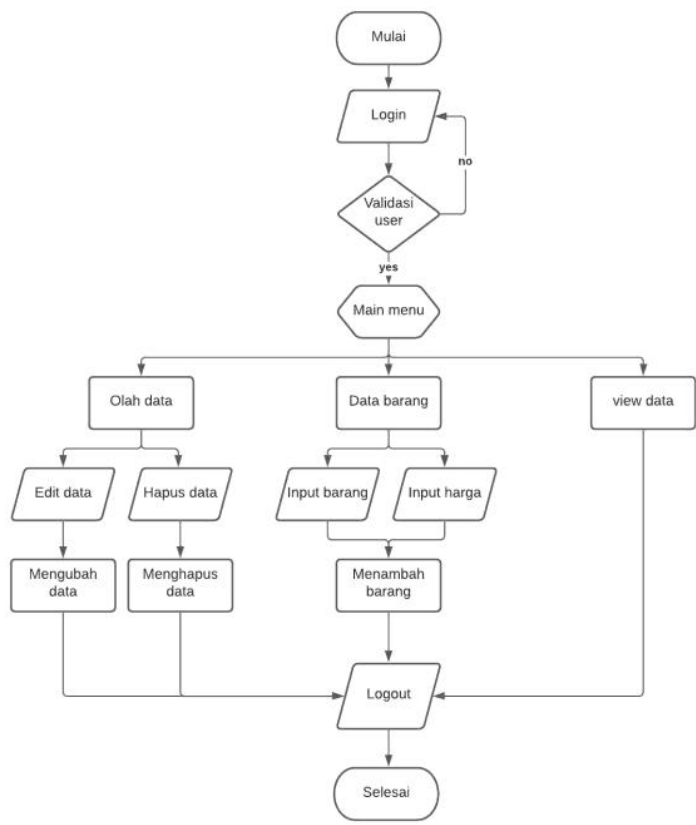

Gambar 3.3 Flowchart pada admin

Penjelasan dari gambar 3.3 yaitu admin memasukkan id dan password untuk login ke admin lalu divalidasi login, selanjutnya admin masuk ke main menu dimana dapat mengakses olah data, data input, dan view data, pada olah data terdapat edit data dan hapus data, pada data input terdapat input barang dan input harga, terakhir pada view data menampilkan data yang telah di input. Setelah proses selesai, admin dapat melakukan logout.

\section{B. DFD Level 1}

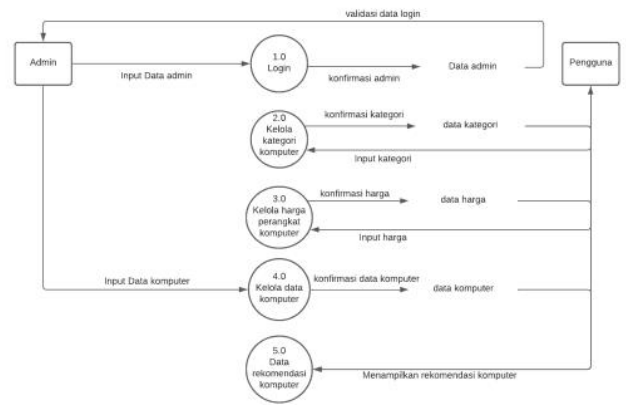

Gambar 3.4 DFD level 1 
Pada DFD level 1 terdapat 2 user yaitu admin sebagai level tertinggi dan pengguna sebagai level biasa. Pengguna memasukkan data kategori komputer dan harga perangkat komputer yang di inginkannya, kemudian data tersebut diolah menghasilkan data rekomendasi komputer dan diterima kepada pengguna. Admin melakukan input data admin berupa username dan password untuk masuk ke sistem pendukung keputusan web. Data admin akan divalidasi ke basis data agar admin mendapatkan akses. Selanjutnya admin melakukan input data komputer, proses ini admin akan membuat data rekomendasi komputer.

\section{Relasi Antar Tabel}

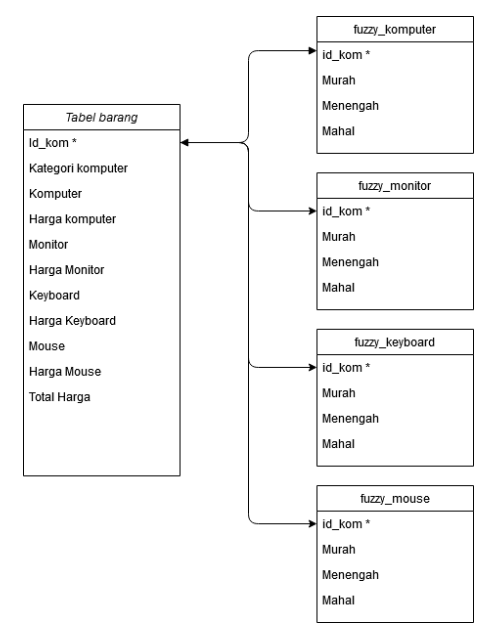

Gambar 3.5 Relasi antar tabel

\section{Implementasi Sistem}

Berikut ini penulis menjelaskan bagaimana penggunaan system keputusan rekomendasi komputer baik untuk pengguna maupun admin. Berikut penjelasannya :

\section{Tampilan pengguna}

Pengguna masuk ke aplikasi sistem keputusan rekomendasi komputer, pengguna dapat memilih kategori komputer yaitu kantor, multimedia, atau gaming, peengguna juga bisa memilih harga tiap komponen komputer sesuai keinginan mulai murah, menengah, hingga mahal. Setelah memilih semua, pengguna dapat menekan tombol "ok".
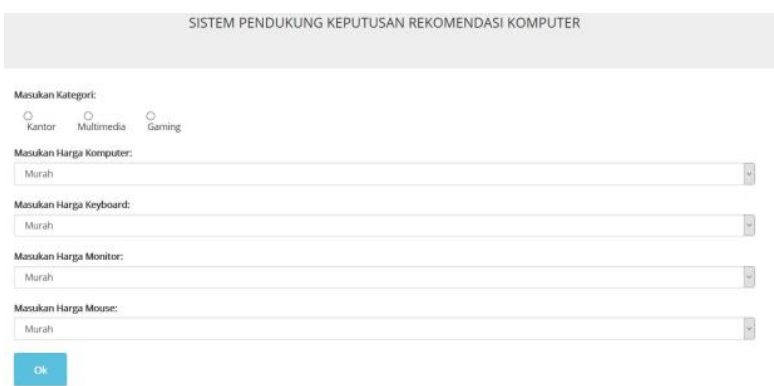

Gambar 3.8 Tampilan aplikasi sistem keputusan rekomendasi komputer

Setelah pengguna mengisi form sistem keputusan rekomendasi komputer, maka muncul list komputer-komputer pilihan yang dapat dipilih oleh pengguna, jika ingin melihat detail spesifikasi komputer tekan tombol "lihat komputer".

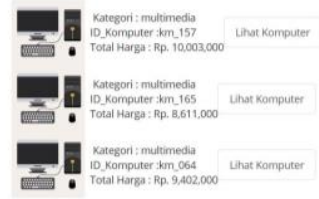

Gambar 3.9 Tampilan list komputer-komputer pilihan sesuai permintaan pengguna

Dihalaman ini pengguna akan ditampilkan spesifikasi komputer yang dia pilih, jika ingin kembali ke menu aplikasi sistem keputusan rekomendasi komputer tekan tombol "kembali ke utama". 


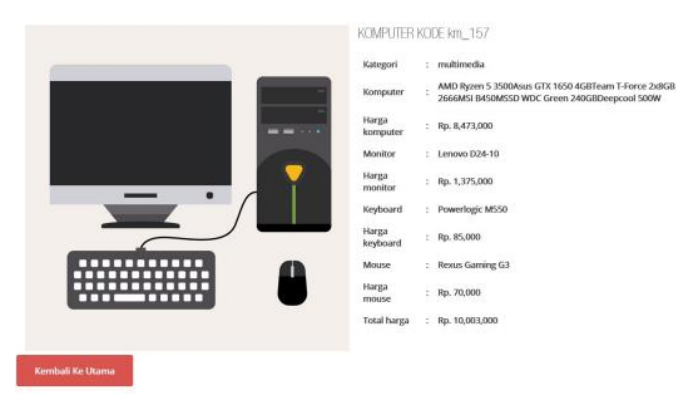

Gambar 3.10 Tampilan spesifikasi komputer

\section{Tampilan admin}

Pada tampilan utama dimana admin dapat menambahkan data, pencarian data, edit data, dan menghapus data.

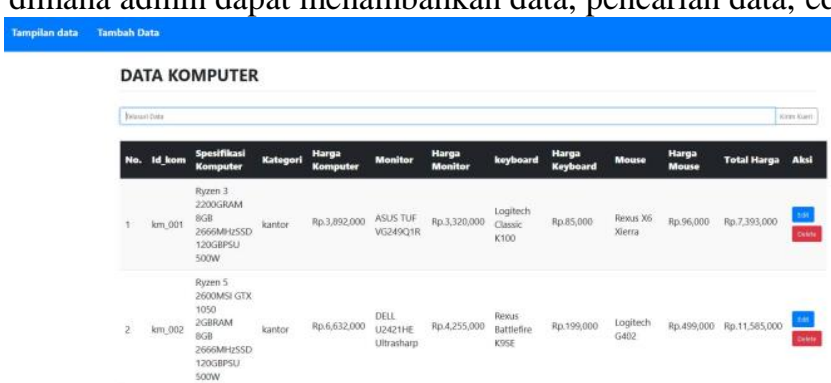

Gambar 3.11 Tampilan utama pada halaman admin

\section{KESIMPULAN}

Kesimpulan yang didapatkan pada pembahasan ini yaitu sistem pendukung keputusan untuk rekomendasi komputer menggunakan metode logika fuzzy tahani berbasis web sebagai berikut : Memiliki tampilan menarik dan dinamis. Mudah digunakan untuk pengguna. Admin cukup memasukan data dan harga tanpa menghitung metode fuzzy tahini. Aplikasi yang ringan cukup dijangkau pengguna

\section{UCAPAN TERIMA KASIH}

Penulis sangat bersyukur kepada Allah SWT karena dapat menyelesaikan jurnal ini dengan lancer, penulis berterima kasih kepada CIPTA MANDIRI COMPUTER untuk datanya diperbolehkan digunakan dalam pembuatan jurnal ini, dan juga berterima kasih kepada dosen pembimbing, orang tua, dan teman-teman untuk supportnya sehingga penulis dapat termotivasi untuk menyelesaikan jurnal ini.

\section{REFERENSI}

[1] Badan Pusat Statistik, Statistik Telekomunikasi Indonesia 2018, 2018.

[2] Ayub Wimatra, Parlin Simanullang and Riyanto Saputro, DASAR DASAR KOMPUTER, 2008.

[3] Niki Ratama and Munawaroh, KONSEP KECERDASAN BUATAN DENGAN PEMAHAMAN LOGIKA FUZZY DAN PENERAPAN APLIKASI, 2019.

[4] Kusumadewi, Sri and Hari Purnomo, Aplikasi LogikaFuzzy Untuk Pendukung Keputusan. Yogyakarta : GrahaIlmu, 2004.

[5] Yosep Bungkus, Lilik Linawati, and Tundjung Mahatma, Program Aplikasi Fuzzy Database Model Tahani Untuk Pemilihan Kendaraan Bermotor Roda Dua Berdasarkan Kriteria Linguistik, 2014.

[6] Ahmad Zainudin, Jurnal DECISION SUPPORT SYSTEM UNTUK MENENTUKAN KELUARGA MISKIN MENGGUNAKAN FUZZY QUERY DATABASE MODEL TAHANI, 2013.

[7] DinKeSos, 2009, Laporan Data Keluarga Miskin, Dinas Kementrian Sosial.

[8] Santoso and Radna Nurmalina, Jurnal "Perencanaan dan Pengembangan Aplikasi Absensi Mahasiswa Menggunakan Smart Card Guna Pengembangan Kampus Cerdas (Studi Kasus Politeknik Negeri Tanah Laut)", 2017.

[9] Jurnal Santoso and Wan Yuliyanti, Perencanaan dan pembuatan aplikasi absensi dosen menggunakan radio frequency identification (RFID) (studi kasus politeknik tanah laut), SENIATI, ITN Malang, 2016, pp E53-1 E53-7.

[10] Fathansyah, Basis Data, Informatika - Bandung, Revisi 3 - 2018. 